\section{Reduction of Listeria innocua contamination in vacuum-pack- aged dry-cured Italian pork products after high hydrostatic pressure treatment}

\author{
Giuseppe Merialdi,' Mattia Ramini,' \\ Emanuela Ravanetti,, Giorgio Gherri, ${ }^{2}$ \\ Paolo Bonilauri' \\ 'Institute for Experimental Veterinary \\ Medicine of Lombardy and Emilia \\ Romagna, Brescia; ${ }^{2} \mathrm{Ham}$ factory San \\ Michele SRL, Lesignano (PR), Italy
}

\section{Abstract}

The present work aims to present the results of the application of a treatment with high hydrostatic pressure (HHP) on Italian fermented and dry-cured pork products. The products used in this study were portioned cured ham, portioned bacon and salami, vacuumpackaged and produced by a single processing company. Two studies were conducted on a single batch of the three products by means of an artificial contamination with Listeria innocua as a surrogate of $L$. monocytogenes. In the first trial a superficial contamination was obtained by immersion for $3 \mathrm{~min}$ in the culture broth with a concentration of approximately 9 $\log \mathrm{cfu} / \mathrm{mL}$. At the end of the inoculum step, the pieces were dred at room temperature and vacuum packaged. In the second trial $50 \mathrm{~kg}$ of minced pork meat were contaminated before production of salami. In both cases the inoculum contained 5 strains of $L$. innocua. Subsequently, in both trials, 10 samples were randomly divided into two groups of 5 pieces each: i) TH group, samples treated with HHP; ii) group $\mathrm{C}$, control samples, not subjected to any treatment. All samples were stored at refrigeration temperature at the end of HHP treatments (if applied), and analyzed for the determination of the surface ( $1^{\text {st }}$ trial) and deep ( $2^{\text {nd }}$ trial) quantitative contamination of L. innocua. $\mathrm{pH}$ and $\mathrm{a}_{\mathrm{W}}$ were also determined on 3 pieces of each products belonging to group $\mathrm{C}$. The difference between the medians of the log $\mathrm{cfu} / \mathrm{cm}^{2}$ or $\mathrm{g}$ established between controls and treated were compared using the non-parametric test (Kruskal-Wallis test) with $\mathrm{P}<0.01$. In all products and in both trials the level of contamination detected in treatment groups was always significantly lower than in controls $(\mathrm{P}<0.01)$. In particular, in vacuum-packaged ham, bacon and salami viability logarithmic viability reductions equal to $-2.29,-2.54$ and -2.51 were observed, respectively. This study aimed to evaluate a not-thermal treatment on
Italian cured or fermented pork products. The results of this study need to be confirmed in different products and in a greater number of lots, but they appear promising, also because of the considerable literature available for different categories of products (cheese, vegetables and fruit).

\section{Introduction}

The application of high hydrostatic pressure (HHP) in food preservation has received particular attention as a viable alternative (economically and technologically) to thermal processes (Patterson, 2005). High pressure processing (HPP) is a non-thermal food preservation method that has gained considerable interest in the last two decades because of its ability to preserve foods while maintaining their fresh-like qualities. Pressures of 300-700 $\mathrm{MPa}$, which inactivate vegetative cells but not bacterial spores, are typically used for food preservation (Stewart and Cole, 2001). Highhydrostatic pressure processing is growing as a processing method or intervention technology of choice because of its demonstrated ability to economically extend shelf life and preserve the quality of food, as heat is not applied. Unlike interventions, such as antimicrobials or oils, which are usually applied to the surface of a food product, HPP operates according to the isostatic principle, in which the pressure applied to a sample through a pressurized medium such as water or oil is instantaneous and uniform throughout the sample, regardless of its volume or shape, thus inactivating microbes throughout a sample (Rastogi et al., 2007).

The application of pressure to a sample through a pressurized fluid via HPP was demonstrated as an effective method for inactivation of pathogens, such as $L$. monocytogenes and spoilage organisms under room temperature conditions, in a variety of food products such as guacamole, sauce, fruit juices, meats, seafood and cheese (Sandra et al., 2004; Rastogi et al., 2007; Zhang and Mittal, 2008; Van Hekken et al., 2013).

Inactivation of microorganisms by HPP has been attributed to cell death i.e. in cheese, has been shown that the treatment lead to a reorganization of water molecules around the ions, changing in the amount of free and unbound water molecules, which affect the mineral balance, enzyme interactions, and protein conformation (Knorr et al., 2006), loss of cytoplasmic membrane integrity and partial loss of membrane integrity. However HPP does not necessarily lead to cell death and a sub-lethal injury to the cells that accounts for the growth of cells after treatment has been observed (Ritz et al., 2001; López-Pedemonte et al., 2007).
Correspondence: Paolo Bonilauri, Institute for Experimental Veterinary Medicine of Lombardy and Emilia Romagna, (IZSLER) via Bianchi 7/9, 25124 Brescia, Italy.

Tel. +39.030.22901 - Fax: +39.030.2425251.

E-mail: paolo.bonilauri@izsler.it

Key words: Listeria innocua; Dry-cured; Pork products; High hydrostatic pressure.

Received for publication: 8 July 2014.

Revision received: 10 February 2015.

Accepted for publication: 10 February 2015.

This work is licensed under a Creative Commons Attribution 3.0 License (by-nc 3.0).

(C) Copyright G. Merialdi et al., 2015

Licensee PAGEPress, Italy

Italian Journal of Food Safety 2015; 4:4515

doi:10.4081/ijfs.2015.4515

The extent of microbial inactivation using HPP is affected by applied pressure, initial substrate temperature, hold time, food substrate and composition, presence of antimicrobial compounds, and pressure resistance of the microorganisms (Smelt, 1998; Chen and Hoover, 2003; Patterson, 2005; Hayman et al., 2007). The water activity $\left(a_{w}\right)$ could be an important factor that can influence the efficacy of HHP treatment. While reduced $\mathrm{a}_{\mathrm{w}}$ can inhibit the growth of microorganisms, it can also protect them from other environmental stresses, such as heat (Gould, 1985). Decreasing $a_{w}$ has also been found to increase the resistance of microorganisms to high pressures (Oxen and Knorr, 1993), however this effect depends on the solute used to depress $\mathrm{a}_{\mathrm{w}}$ (Patterson, 2005; Koseki and Yamamoto, 2007).

In Italian typical pork productions such as salami, bacon and ham, lactic fermentation and/or $a_{w}$ reduction are used to stabilize and transform the products, but survival or recontamination with $L$. monocytogenes can occur in different steps of the production process.

European Union food regulation admits the presence of $L$. monocytogenes below concentrations of 100 colony-forming units (cfu)/g in ready to eat (RTE) products if they do not sustain the growth of the pathogen above the limit during their shelf life. In USA a zero tolerance policy is applied and the presence of L. monocytogenes in RTE product is not admitted.

The aim of this research was to apply a treatment with HHP on Italian fermented and dry-cured products to evaluate the efficacy of the treatment on the reduction of superficial and deep (in the cases of salami) contamination of $L$. innocua, used as a surrogate for $L$. monocytogenes (Scott et al., 2005). 


\section{Materials and Methods}

Two trials were conducted. The first was addressed to establish the efficacy of HHP treatment on superficial contamination of $L$. innocua as a surrogate for $L$. monocytogenes on vacuum-packaged portioned ham, bacon and salami. The second was addressed to establish the efficacy of HHP treatment on salami produced after contamination of minced pork meat with $L$. innocua as a surrogate for $L$. monocytogenes.

\section{Products}

Pork meat salami, bacon and ham coming from a single producer (one batch per each product) were used in the study (Table 1). For the first trial ten portion of $200 \mathrm{~g}$ of vacuumpackaged salami, bacon and ham were randomly divided into 2 groups of 5 pieces: i) high hydrostatic pressure treatment (TH group), samples treated with HHP; ii) Group C, control samples not subjected to any treatment. For the second trial, salami were produced from 50 $\mathrm{kg}$ of minced pork meat and after the curing period, were divided into the same 2 groups, TH and control groups, of 5 pieces each.

\section{Inoculum}

Five strains of $L$. innocua (IZSLER 111373/1 and IZSLER 111373/2 isolated in superficial swab collected in pork meat transformation plant, IZSLER 257529/1 isolated form pork fresh sausages, IZSLER 257529/2 isolated from fresh pork meat and a collection strain ATCC 33090 ) were streaked for colony isolation onto a non-selective agar plate (Trypticase soy agar) and incubated for $24-48 \mathrm{~h}$ at $37^{\circ} \mathrm{C}$. Revitalized strains were inoculated in a $1 \mathrm{~L}$ of non-selective nutrient broth (Brain Heart Infusion) and incubated at $37^{\circ} \mathrm{C}$ for $24-26 \mathrm{~h}$ to obtain stationary cells at approximately $1 \times 10^{9}$ cells/mL. At contamination time, a cocktail of the 5 broths culture was obtained and used for contamination. For the first trial, 5 pieces of the three products were surface inoculated by dipping the portioned foods into the inoculation suspension (cocktail of the 5 broth culture) for $3 \mathrm{~min}$. A post-inoculation drying and attachment period of 30 min was applied. After that, each piece was re- vacuum-packaged and put at refrigeration temperature $\left(4 \pm 2^{\circ} \mathrm{C}\right)$ until treatment. For the second trial, $100 \mathrm{~mL}$ of inoculation suspension (cocktail of the 5 broth culture) were added to a $50 \mathrm{~kg}$ of minced pork meat and fat suitable for salami production. The distribution of the inoculum was homogenized throughout $30 \mathrm{sec}$ of mechanically homogenizer. Salami were dry-cured after 3 days of drying and ripened for 4 weeks following the producers' protocols.

\section{High hydrostatic pressure treatment}

The HHP treatment (TH group) consisted of 6000 bar for $360 \mathrm{sec}$. The pressure-holding treatment time in this study did not include the pressure increase time or the decompression time. The temperature reached by the product was not determined, while the water temperature during the process started from 12 to $13^{\circ} \mathrm{C}$, grew until $31^{\circ} \mathrm{C}$ during the treatment, and immediately returned to $12^{\circ} \mathrm{C}$ after the end of pressure stress. The contribution of estimated highest sample temperature to the destruction of microorganisms by HHP was considered negligible.

\section{Enumeration of Listeria innocua}

Each vacuum-packaged piece was open after ethanol-sterilization. A superficial portion of approximately $100 \mathrm{~cm}^{2}$ was sliced and an analytical portion of $25 \mathrm{~cm}^{2}$ was obtained and submitted for $L$. innocua enumeration procedure. Due to the absence of a specific method for $L$. innocua enumeration, IS011290-2:1998/Amd 1:2004 (IS0, 2004) for L. monocytogenes enumeration was used until spread plated onto ALOA agar. All plates were incubated at $37^{\circ} \mathrm{C}$ for $48 \mathrm{~h}$ and typical L. innocua colonies (green on ALOA agar not surrounded by any opaque halo) were counted manually and submitted to biochemical confirmatory test (API® listeria; bioMérieux Clinical Diagnostics, Marci l'Etoile, France). Bacterial numbers were expressed as the logarithm of $\mathrm{cfu} / \mathrm{g}$.

\section{Statistical analysis}

The difference between the medians of $\log$ $\mathrm{cfu} / \mathrm{cm}^{2}$ of $L$. innocua between control and treated groups was compared using the nonparametric test (Kruskal-Wallis test) with Intercooled Stata 7.0 software (Stata Corporation, College Station, TX, USA). Significance was established at $\mathrm{P}<0.01$.

\section{Results}

In Table 2 the results obtained in the two trials are summarized. In particular, contamination in control group results in the whole experiment significantly $(\mathrm{P}<0.01)$ reduced after HHP treatment, regardless of the type of food product or the type of contamination (superficial or deep in the case of repined sala$\mathrm{mi})$.

\section{Discussion}

The results show that the applied HHP treatment is able to reduce both superficial and deep contamination of $L$. innocua in all the products. A similar result was previously obtained for different types of food such as guacamole, sauce, fruit juices, meats, seafood and cheese (Sandra et al., 2004; Rastogi et al., 2007; Zhang and Mittal, 2008; Van Hekken et al., 2013). On salami and pork meat transformed products such as ham only few references are available. In particular in Bover-Cid et al. (2011) a model of $L$. monocytogenes inactivation on dry-cured ham by HHP processing is developed and the conclusion of this model fits exactly what is observed in our experiment. In particular the model predicts a treatment able to obtain $2.39 \mathrm{D}$ reduction through a HHP at $613 \mathrm{MPa}$ for $5 \mathrm{~min}$. In our study a similar treatment $(6000 \mathrm{bar}$ - correspond to $600 \mathrm{Mpa}$, per $360 \mathrm{sec}$ ) was able to obtain on average $2.44 \mathrm{D}$ reduction in portioned ham, bacon or salami and $2.76 \mathrm{D}$ reduction in deep contaminated salami.

The presence of $L$. monocytogenes in RTE Italian pork meat products is reported and the

Table 1. Products details.

\begin{tabular}{lcc} 
Product & Fat content $(\%)$ & Ripening period \\
Pork meat salami & 30.0 & 50 days at $12-13^{\circ} \mathrm{C}$ \\
Bacon & 55.1 & 90 days at $15^{\circ} \mathrm{C}$ \\
\hline Ham & 13.7 & 80 days at $14-16^{\circ} \mathrm{C}$ followed by 9 months at $18^{\circ} \mathrm{C}$ \\
\hline
\end{tabular}

Table 2. Results of contamination of Listeria innocua in controls and vacuum-packaged products treated with high hydrostatic pressure.

\begin{tabular}{lccccc} 
& Control & TH group & D Log $\mathbf{N} / \mathbb{N}_{0}$ & $p H$ & $\mathbf{a}_{w}$ \\
Ham & $5.108 \pm 0.099^{\mathrm{a}}$ & $2.818 \pm 0.591^{\mathrm{b}}$ & -2.29 & $6.267 \pm 0.057$ & $0.922 \pm 0.002$ \\
Bacon & $5.632 \pm 0.115^{\mathrm{a}}$ & $3.096 \pm 0.861^{\mathrm{b}}$ & -2.54 & $5.967 \pm 0.058$ & $0.933 \pm 0.002$ \\
\hline Salami (superficial) & $4.924 \pm 0.201^{\mathrm{a}}$ & $2.416 \pm 0.456^{\mathrm{b}}$ & -2.51 & $5.9 \pm 0.1$ & $0.922 \pm 0.002$ \\
Salami (deep) & $5.040 \pm 0.321^{\mathrm{a}}$ & $2.280 \pm 0.164^{\mathrm{b}}$ & -2.76 & $5.867 \pm 0.115$ & $0.923 \pm 0.002$ \\
\hline
\end{tabular}

TH group, high hydrostatic pressure treatment; $\mathrm{a}_{w}$, water activity. Values are expressed as mean \pm standard deviation $\log 10 \mathrm{cfu} / \mathrm{cm}^{2} \mathrm{or} \mathrm{g}$ $a, b$ Means with different lowercase letter in the same rows differ significantly at $\mathrm{P}<0.01$ (Kruskal-Wallis test). 
microorganism can survive in cured products such as salami for a long period (Gianfransceschi et al., 2006). Moreover, postproducing manipulation, such as portioning, slicing and packaging of food products can enable cross-contamination and serve as a source for the spread of the pathogen (Vorst $e t$ al., 2006). When meat products are re-contaminated during post-processing and producing manipulation the contamination is assumed to be $10 \mathrm{cfu} / \mathrm{g}$ (i.e. $1 \mathrm{Log} \mathrm{cfu} / \mathrm{g}$ ) at the worst (ICMSF, 1996). In this way, Hoz et al. (2008) proposed a $2.39 \mathrm{D}$ process to meet the USA zero tolerance policy, which can be achieved in drycured ham, through a HHP at $613 \mathrm{MPa}$ for 5 min according to the model proposed by BoverCid et al. (2011).

Taking into consideration the European Union microbiological criteria in relation to $L$. monocytogenes, a maximum tolerance of 100 $\mathrm{cfu} / \mathrm{g}$ is admitted. The low concentration of $L$. monocytogenes in meat RTE products (Casadei et al., 2004; EFSA, 2013) considered and the effect recorded in this study given, it can be stated that HHP treatment can greatly contribute to reduce or eliminate the risk of exposure for consumers.

\section{Conclusions}

In conclusion, the results of this study indicate that HHP could be profitably applied to Italian typical pork products in order to reduce L. monocytogenes contamination as largely demonstrated for many other food products. Anyway, it is worthy to note that the results of this study need to be confirmed in different products and in a greater number of lots.

\section{References}

Bover-Cid S, Belletti N, Garriga M, Aymerich T, 2011. Model for Listeria monocytogenes inactivation on dry-cured ham by high hydrostatic pressure processing. Food Microbiol 28:804-9.

Casadei L, Merialdi G, Bonilauri P, Palomba A, Bergomi S, Rosi M, Dottori D, 2004. Contaminazione da Listeria monocytogens in alimenti di origine animale e prevalenza dei diversi sierotipi. L'igiene moderna 122:71-85.

Chen H, Hoover DG, 2003. Modeling the combined effect of high hydrostatic pressure and mild heat on the inactivation kinetics of Listeria monocytogenes Scott A in whole milk. Innov Food Sci Emerg 4:25-34.

EFSA, 2013. Analysis of the baseline survey on the prevalence of Listeria monocytogenes in certain ready-to-eat foods in the EU, 2010-2011. Part A: Listeria monocytogenes prevalence estimates. EFSA J 11:3241.

Gianfransceschi M, Gattuso A, Fiore A, D'Ottavio MC, Casale M, Palumbo A, Aureli P, 2006. Survival of Listeria monocytogenes in uncooked Italian dry sausage (salami). J Food Protect 69:1533-8.

Gould GW, 1985. Present state of knowledge of aw effects on microorganisms. In: Simatos D, Multons JL, eds. Properties of water in foods. Martinus Nijhoff Publ., Dordrecht, The Netherlands, pp 229-45.

Hayman MM, Anantheswaran RC, Knabel SJ, 2007. The effect of growth temperature and growth phase on the inactivation of Listeria monocytogenes in whole milk subject to high pressure processing. Int J Food Microbiol 115:220-6.

ICMSF, 1996. Microorganisms in foods, 5. Microbiological specifications of food pathogens. Blackie Academic \& Professional, London, UK, pp 141-82

ISO, 2004. Modification of the enumeration medium. ISO Norm 11290-2:1998/Amd 1:2004. International Organization for Standardization, Geneva, Switzerland.

Knorr D, Heinz V, Buckow R, 2006. High pressure application for food biopolymers. Biochim Biophys Acta 1764:619-31.

Koseki S, Yamamoto K, 2007. Water activity of bacterial suspension unable to account for the baroprotective effect of solute concentration on the inactivation of Listeria monocytogenes by high hydrostatic pressure. Int J Food Microbiol 115:43-7.

Hoz L, Cambero MI, Cabeza MC, Herrero AM, Ordóñez JA, 2008. Elimination of Listeria monocytogenes from vacuum-packed drycured ham by e-beam radiation. J Food Protect 71:2001-6.

López-Pedemonte T, Roig-Sagués A, De Lamo S, Hernández-Herrero M, Guamis B, 2007.
Reduction of counts of Listeria monocytogenes in cheese by means of high hydrostatic pressure. Food Microbiol 24:59-66.

Oxen P, Knorr D, 1993. Baroprotective effects of high solute concentrations against inactivation of Rhodotorula rubra. Lebensm Wiss Technol 2:220-3.

Patterson MF, 2005. Microbiology of pressuretreated foods. J Appl Microbiol 98:1400-9.

Rastogi NK, Raghavarao KSMS, Balasubramaniam VM, Niranjan K, Knorr $\mathrm{D}, 2007$. Opportunities and challenges in high pressure processing of foods. Crit Rev Food Sci 47:69-112.

Ritz M, Tholozan JL, Federighi M, Pilet MF, 2001. Morphological and physiological characterization of Listeria monocytogenes subjected to high hydrostatic pressure. Appl Environ Microb 67:2240-7.

Sandra S, Stanford MA, Meunier Goddik L, 2004. The use of high-pressure processing in the production of Queso Fresco cheese. J Food Sci 69:153-8.

Scott VN, Swanson K, Frier TA, Pruett jr WP, Sveum WH, Hall PA, Smoot LA, Brown DG, 2005. Guidelines for conducting Listeria monocytogenes challenge testing of foods. Food Protect Trends 25:818-25.

Smelt JPPM, 1998. Recent advances in the microbiology of high pressure processing. Trends Food Sci Tech 9:152-8.

Stewart CM, Cole MB, 2001. Preservation by the application of nonthermal processing. In: Moir CJ, Andrew-Kabilafkas C, Arnold G, Cox BM, Hocking AD, Jenson I, eds. Spoilage of processed foods: causes and diagnosis. AIFST Inc. (NSW) Food Microbiology Group, Sydney, Australia, pp 53-61.

Van Hekken DL, Tunick MH, Farkye NY, Tomasula PM, 2013. Effect of hydrostatic high-pressure processing on the chemical, functional, and rheological properties of starter-free Queso Fresco. J Dairy Sci 96:6147-60.

Vorst KL, Todd ECD, Ryser ET, 2006. Transfer of Listeria monocytogenes during mechanical slicing of turkey breast, bologna, and salami. J Food Protect 69:619-26.

Zhang H, Mittal GS, 2008. Effects of high-pressure processing (HPP) on bacterial spores. Food Rev Int 24:330-51. 